\title{
Incidence, Types and Levels of Aflatoxin in Different Peanuts Varieties Produced in Busia and Kisii Central Districts, Kenya
}

\author{
Nelson C. Menza1 ${ }^{*}$, Muturi W. Margaret ${ }^{1}$, Kamau M. Lucy ${ }^{2}$ \\ ${ }^{1}$ Department of Medical Laboratory Sciences, Kenyatta University, Nairobi, Kenya \\ ${ }^{2}$ Department of Zoological Sciences, Kenyatta University, Nairobi, Kenya \\ Email: "menza.nelson@ku.ac.ke, muturi.margaret@ku.ac.ke, kamau.lucy@ku.ac.ke
}

Received 17 August 2015; accepted 1 December 2015; published 4 December 2015

Copyright (C) 2015 by authors and Scientific Research Publishing Inc.

This work is licensed under the Creative Commons Attribution International License (CC BY). http://creativecommons.org/licenses/by/4.0/

(c) (i) Open Access

\section{Abstract}

Busia and Kisii Central districts are areas in western Kenya that have repeatedly reported high levels of stunting growth in children and an increase in hepatocellular carcinoma (HCC); an aspect often positively associated with chronic exposure to aflatoxins especially through consumption of foods such as peanuts. The objectives of the study were to determine the incidence, types and levels of aflatoxin in different varieties of peanuts produced in Busia and Kisii Central districts. One hundred and two (102) peanuts samples were collected from farmers' in each district. Aflatoxin types and levels of aflatoxins were analyzed using high performance liquid chromatography (HPLC) technique. All the peanuts samples from Kisii Central and $97.06 \%$ samples from Busia were contaminated with aflatoxins. However, aflatoxin was not detected in $2.94 \%$ of samples from Busia district. The levels of total aflatoxin ranges were 0.1 to $268 \mu \mathrm{g} / \mathrm{kg}$ and 1.63 to $591.1 \mu \mathrm{g} / \mathrm{kg}$ in peanuts from Busia and Kisii Central respectively. Majority of peanuts samples had levels within Kenya Bureau of Standards (KEBS) and European Union (EU) regulatory limits for total aflatoxins. Improved variety (Valencia red) had significantly lower aflatoxin contamination compared to local varieties (Uganda local red, Homabay local and Local red). Aflatoxins B1, B2, G1 and G2 were found in peanuts; $B 1$ was the most predominant in both districts $(t=12.4, \mathrm{df}=3, \mathrm{P}=0.034)$. The levels of aflatoxins especially in peanuts from Kisii Central district were high $(591.1 \mu \mathrm{g} / \mathrm{kg})$ where 44.6\% of samples analyzed were unfit for even animal feed (USFDA regulatory limit). An assessment on the levels of aflatoxins should be done by the relevant stakeholders in other key foods in the areas for example maize. The most lethal aflatoxin type B1 was found to be the most predominant peanuts from both districts of study. This calls for frequent aflatoxin screening of peanuts from the districts particularly aflatoxin type $B$.

${ }^{*}$ Corresponding author.

How to cite this paper: Menza, N.C., Margaret, M.W. and Lucy, K.M. (2015) Incidence, Types and Levels of Aflatoxin in Different Peanuts Varieties Produced in Busia and Kisii Central Districts, Kenya. Open Journal of Medical Microbiology, 5, 209221. http://dx.doi.org/10.4236/ojmm.2015.54026 


\section{Keywords}

\section{Levels of Aflatoxins, Peanuts, Aflatoxin Type B1}

\section{Introduction}

Aflatoxins are hepatotoxic and highly carcinogenic mycotoxins that are produced by Aspergillus species, specifically Aspergillus flavus and Aspergillus parasiticus. Aflatoxins contamination of foods including peanuts are major hazards to human health and has been associated with liver failure, stunted growth in children, hepatocellular carcinoma (HCC) and death [1]. It has been estimated that more than 5 billion people in developing countries worldwide are at risk of chronic exposure to aflatoxins through contaminated foods [2] [3]. Aflatoxins are produced in food crops such as peanuts when they are poorly dried and stored [4]. Aflatoxins can be produced at both the pre- and post-harvest stages [5].

Kenya has repeatedly experienced epidemics of acute aflatoxicosis especially in the Eastern province in the years 2001, 2004, 2005 and 2006 [6] [7]. The largest outbreak due to maize aflatoxin poisoning was reported in the year, 2004 where 125 people died out of the 317 reported cases [8]. Studies conducted in other developing countries established a relationship between aflatoxin exposure and the prevalence of hepatocellular carcinoma [9]. While this severe outbreak was devastating, more individuals still suffer from diseases associated with low chronic levels of aflatoxin consumption in crop produce [7].

In the western Kenya, peanuts play a key role in food security after maize due to its capability for production even during the dry seasons. Peanuts in the region are mainly used in relishes served with the staple maize porridge commonly known as ugali or ground and made into sauce [10]. Western Kenya particularly in Busia and Kisii Central districts have repeatedly reported high levels of stunting growth in children [10], an aspect often positively correlated with long-term ingestion of sub-lethal doses of aflatoxins [11]. In addition, studies carried out in the region have shown that aflatoxin levels in peanuts exceed the minimum acceptable limits of $10 \mu \mathrm{g} / \mathrm{kg}$ total aflatoxins, according to KEBS, 2007 [12] which results in outbreaks of aflatoxicosis [13]. Despite the increase in aflatoxin levels, there is limited published information on the incidence, levels and types of aflatoxins contaminating peanuts. The present study therefore was designed to determine the incidence aflatoxins, types and levels of aflatoxins in the different varieties of peanuts produced in Busia and Kisii Central districts.

\section{Materials and Methods}

\subsection{Study Areas}

The study was conducted in two districts in western Kenya namely Busia and Kisii Central which represented Busia and Kisii counties respectively. Western Kenya encompasses Nyanza and Western provinces which are the main peanut producing areas in Kenya [14]. Nyanza Province which encompasses Kisii Central district is the country's largest peanut producer with 14,723 hectares under production and has several peanut processors as well as a high demand for peanuts and their products.

\subsection{Study Design}

A cross-sectional study was adopted among the peanuts farmers in Busia and Kisii Central districts.

\subsection{Study Population}

The study comprised of peanuts farmers/producers in Busia and Kisii Central districts. The number of farmers/producers growing groundnuts varied between different agro-ecological zones (divisions) within each district. The agro-ecological zones were determined based on altitude, mean annual rainfall, temperature and probability of successful growing of peanuts in that zone. The peanuts production statistics of farmers were obtained from the division's agricultural offices.

\subsection{Sampling Technique}

Peanuts farmers' households were sampled from the agro-ecological zones (divisions). In Busia, farmers in the 
leading groundnut producing divisions identified as Butula, Matayos, Funyula and Budalangi were purposively selected. The other division in Busia (Township) had only small areas under groundnuts cultivation and was therefore, not included in the study. In Kisii, farmers in the four leading peanut producing divisions; Keumbu, Masimba, Suneka and Mosocho were also purposively sampled. The other divisions in the district (Kisii Town and Marani) were excluded from the study due to small areas under groundnuts production. Within the divisions (agro-ecological zones) selected in both Busia and Kisii Central districts, peanuts farmers households were randomly selected by staggering every fourth household within the division administrative boundary, the starting point being the fourth household from the division's agricultural office in the particular divisions. The sampling interval was obtained based on the approximate peanuts farmers' population of 408 in the study areas [15] divided by the sample size (102).

\subsection{Study Approval, Ethical Consideration and Informed Consent}

Ethical approval was obtained from Kenyatta University Ethics Review Committee. Research permit was obtained from the National Commission for Science, Technology and Innovation (NACOSTI) Kenya. The study objectives were explained to the peanuts farmers and they were allowed to ask questions. After giving consent, the participants signed a consent form and peanuts samples were collected.

\subsection{Laboratory Procedure}

\subsubsection{Sample Collection}

A total of 102 peanut samples from peanut farmers' household in each study district were collected using the procedure of Whitaker, 2006 [16]. Peanuts stored in sacks or boxes was sampled from different parts using a closed spear driven through the top and sides of each sack or box to obtain a total of $0.5 \mathrm{~kg}$ of sample. Each of the $0.5 \mathrm{~kg}$ samples of unsorted peanuts was put in clean polyethylene bags, sealed, labeled and transported in cool boxes. The peanut samples were taken to Bora Limited Laboratory, Nairobi and University of Nairobi, Department of Food Science, Nutrition and Technology and stored at $4^{\circ} \mathrm{C}$ until the time of analysis for incidence, types and levels of aflatoxins in peanuts.

\subsubsection{Aflatoxin Analysis}

Each homogenized grounded peanut sample was triturated and analyzed to determine the types and levels of aflatoxin contaminants.

\section{1) Extraction of Aflatoxins from Peanuts Powder}

Approximately fifty grams from each homogenized peanuts sample was triturated in a blender in $50 \mathrm{ml}$ of $70 \%$ methanol (70 ml absolute methanol mixed in $30 \mathrm{ml}$ distilled water) containing $0.5 \%$ potassium chloride until thoroughly homogenized. The extract was transferred to a conical flask and centrifuged at $300 \mathrm{rpm}$ for $30 \mathrm{mi}-$ nutes to remove any particulates. The extract was filtered through Whatman No. 4 filter paper and diluted 1:10 in phosphate buffered saline containing $500 \mu \mathrm{l} / \mathrm{L}$ Tween-20 and analyzed for aflatoxins using High Performance Liquid Chromatography (HPLC).

\section{2) Identification and Quantification of Aflatoxins}

High Performance Liquid Chromatography (HPLC) was used to confirm identity of the aflatoxin and quantified using the method of Bragulat et al., 2001 [17]. HPLC system consisted of a Hewlett Packard 1100 pump (Palo Atto, CA, USA) connected to an HP 1046A programmable fluorescence detector and quantification was done with an HP workstation. Twenty microliters $(20 \mu \mathrm{l})$ of each extract was applied to HPLC and chromatographic separation was performed on a stainless steel C18 reversed phase analytical column $(150 \times 4.6 \mathrm{~mm}, 5$ $\mu \mathrm{m}$ particle size) preceded by a C18 pre-column (Ultrasep $104 \mathrm{~mm}$ ). Water: methanol: acetonitrile (4:1:1, v/v/v) was used as the mobile phase at a flow rate of $1.5 \mathrm{~mL} / \mathrm{min}$. Fluorescence of aflatoxin derivatives was recorded at excitation and emission wavelengths of $360 \mathrm{~nm}$ and $440 \mathrm{~nm}$ respectively. Aflatoxins were quantified based on HPLC fluorometric response compared with aflatoxin standards (Sigma chemical, St. Louis, MO, USA). The limit of detection was $0.005 \mu \mathrm{g} / \mathrm{kg}$ for AFB1 and AFG1, and $0.02 \mu \mathrm{g} / \mathrm{kg}$ for AFB2 and AFG2.

\subsection{Data Analysis}

Data on the content of aflatoxin in all peanut samples were recorded and categorized into three: $\leq 4 \mu \mathrm{g} / \mathrm{kg},>4$ 
$\mu \mathrm{g} / \mathrm{kg}$ to $\leq 10 \mu \mathrm{g} / \mathrm{kg}$ and $>10 \mu \mathrm{g} / \mathrm{kg}$. The $\leq 4 \mu \mathrm{g} / \mathrm{kg}$ threshold represents the EU regulatory limit for total aflatoxin while the $\leq 10 \mu \mathrm{g} / \mathrm{kg}$ threshold represents the KEBS regulatory limit for total aflatoxin. The distribution of samples in the levels of aflatoxins were determined using Mann-Whitney $U$ test and the most dominant aflatoxin type in peanuts was analyzed using t-test. Aflatoxin B1 levels in peanuts was categorized into two: $\leq 5 \mu \mathrm{g} / \mathrm{kg}$ and $>5 \mu \mathrm{g} / \mathrm{kg}$. The $\leq 5 \mu \mathrm{g} / \mathrm{kg}$ threshold represents the KEBS regulatory limit for aflatoxin B1 in foods intended for human consumption. All the statistical analysis was done using MINITAB and SPSS version 19.0 computer package.

\section{Results}

\subsection{Peanuts Varieties from Busia and Kisii Central Districts}

A total of 204 peanut samples of different varieties were collected in the two districts. In Busia district, the 102 peanuts samples were of four different varieties; Valencia red, Uganda local, Homabay local and Local red. The 102 peanuts samples from Kisii Central district were of three different varieties; Valencia red, Uganda local and Homabay local. In both districts, Valencia red variety had the most number of the samples, 59 and 89 from Busia and Kisii Central districts respectively which were significantly different from the other varieties $\left(\chi^{2}=12.00\right.$, $\mathrm{df}=9, \mathrm{P}=0.02$ ). There were more samples of Uganda local red (21) and Homabay local (20) varieties from Busia district compared to those from Kisii Central district. Local red variety had only 2 samples in Busia and none in Kisii Central (Table 1).

\subsection{Incidence of Aflatoxin in Peanuts from Busia and Kisii Central Districts}

Aflatoxin was detected in almost all the peanut samples collected from both districts. All the peanuts samples from Kisii Central district and 99 (97.06\%) samples from Busia district were contaminated with aflatoxins (Figure 1). However, aflatoxin was not detected in only 3 (2.94\%) peanuts samples from Busia district.

\subsection{Levels and Types of Aflatoxins Contaminating the Different Varieties of Peanut in Busia and Kisii Central Districts}

The levels and types of aflatoxins analyzed were compared with the Kenya Bureau of Standards (KEBS), Euro-

Table 1. Peanut varieties from busia and kisii central districts.

\begin{tabular}{cccc}
\hline & \multicolumn{3}{c}{ Number of peanut samples collected } \\
\cline { 2 - 4 } Peanut variety & Busia & Kisii central & Total \\
\hline Valencia red $^{\mathrm{a}}$ & 59 & 89 & 148 \\
Uganda local red & 21 & 5 & 26 \\
Homa Bay local & 20 & 8 & 28 \\
Local red & 2 & 0 & 2 \\
Total & $\mathbf{1 0 2}$ & $\mathbf{1 0 2}$ & $\mathbf{2 0 4}$ \\
\hline
\end{tabular}

${ }^{\mathrm{a}}=$ peanut variety with a significantly higher number of samples in the study.

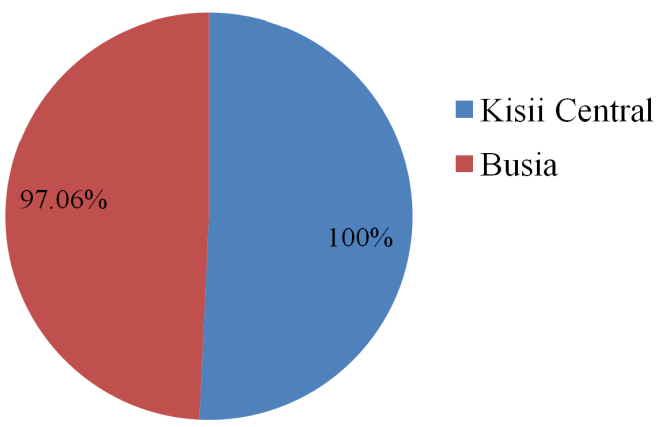

Figure 1. Peanut samples from the two districts contaminated with aflatoxin. 
pean Union (EU) and United States Food and Drug Administration (USFDA) regulatory limits for total and types of aflatoxins in foods for human consumption.

\subsubsection{Peanuts of Different Varieties with Detectable Levels of Aflatoxin}

Two hundred and one (201) samples of different peanuts varieties obtained from both Busia and Kisii Central districts had detectable levels of aflatoxins. Out of the 201 samples, 99 (49.3\%) samples of different peanuts varieties were from Busia district while 102 (50.7\%) were from Kisii Central district. The numbers of peanut samples with detectable levels of aflatoxin in the two districts were compared using a paired sample t-test which showed no significant difference in the number of peanut samples of known varieties with detectable levels of aflatoxin in the two districts $(\mathrm{t}=0.07, \mathrm{df}=1, \mathrm{P}=0.947)$.

One-Way ANOVA test showed that Valencia red variety had a significantly higher rate of aflatoxin contamination than the other varieties, 89 (87.3\%) and 58 (58.6\%) for this variety of peanuts from Kisii Central and Busia respectively $(\mathrm{F}=13.15, \mathrm{df}=3, \mathrm{P}=0.015)$. Peanuts of Homabay local and Uganda local red varieties from Busia had a significant number of peanuts contaminated with aflatoxins (Table 2) compared to those from Kisii Central $\left(\chi^{2}=5.12, \mathrm{df}=1, \mathrm{P}=0.017\right)$. The 2 peanuts samples (2\%) of Local red variety from Busia district had detectable levels of aflatoxins (Table 2).

\subsubsection{Total Aflatoxins in Different Varieties of Peanuts from the Two Study Districts}

The levels of total aflatoxin were in the ranges of 0.1 to $268 \mu \mathrm{g} / \mathrm{kg}$ and 1.63 to $591.1 \mu \mathrm{g} / \mathrm{kg}$ in samples from Busia and Kisii Central districts respectively. Two samples of the Local red variety from Busia district had the highest level of aflatoxins at $267 \mu \mathrm{g} / \mathrm{kg}$ and $268 \mu \mathrm{g} / \mathrm{kg}$. Four (4) samples of Valencia red variety had aflatoxin levels of between 252.8 - $262 \mu \mathrm{g} / \mathrm{kg}$ while 4 samples of Uganda local red variety had aflatoxin levels in the range of $137.4 \mu \mathrm{g} / \mathrm{kg}$ to $137.5 \mu \mathrm{g} / \mathrm{kg}$. Peanuts of Homabay local variety had lower levels of aflatoxins ranging from $1.1 \mu \mathrm{g} / \mathrm{kg}$ to $133.4 \mu \mathrm{g} / \mathrm{kg}$. Peanuts samples (44.6\%) which had total aflatoxins levels exceeding $100 \mu \mathrm{g} / \mathrm{kg}$ were unsuitable also for animal feed according to the US Food and Drug Administration agency (USFDA) regulatory limit.

Peanut samples of the different varieties were grouped into four based on threshold of the total aflatoxins $(\leq 4$ $\mu \mathrm{g} / \mathrm{kg},>4$ to $\leq 10 \mu \mathrm{g} / \mathrm{kg},>10$ to $\leq 20 \mu \mathrm{g} / \mathrm{kg}$ and $>20 \mu \mathrm{g} / \mathrm{kg}$. The $\leq 4 \mu \mathrm{g} / \mathrm{kg}$ is the limit set by European Union; $\leq 10$ $\mu \mathrm{g} / \mathrm{kg}$, Kenya Bureau of Standards while $\leq 20 \mu \mathrm{g} / \mathrm{kg}$ is limit by the United States Food and Drug Administration regulatory requirement for total aflatoxins in foods including peanuts for human consumption (Table 3).

Approximately $80 \%$ of samples of Valencia red and $76 \%$ of Homabay local varieties from Busia district had total aflatoxins of $\leq 4 \mu \mathrm{g} / \mathrm{kg}$ and therefore were fit for human consumption based on the EU total aflatoxins regulatory limits $(\leq 4 \mu \mathrm{g} / \mathrm{kg})$. The two samples of Local red variety from Busia had total aflatoxins levels exceeding $\leq 4 \mu \mathrm{g} / \mathrm{kg}$ and therefore unfit for human consumption based on the EU regulatory limits (Table 3). From Kisii Central district, all samples of Uganda local red and Homabay local peanut varieties had total aflatoxin levels exceeding the EU regulatory limits of $\leq 4 \mu \mathrm{g} / \mathrm{kg}$. Only $5.6 \%$ samples of Valencia red from this district had total aflatoxins within the EU regulatory limit (Table 3). Mann-Whitney $U$ two sample test showed that the number of peanut samples from Busia district in $\leq 4 \mu \mathrm{g} / \mathrm{kg}$ total aflatoxin category was significantly higher compared to Kisii Central ( $\mathrm{W}=222.0$, P = 0.036).

Based on KEBS regulatory limits for total aflatoxins $(\leq 10 \mu \mathrm{g} / \mathrm{kg})$, all peanuts samples, 20 (100\%) of Homabay local variety from Busia district were within the KEBS regulatory limits. Two (100\%) samples of local red

\begin{tabular}{ccccc} 
Table 2. Peanuts samples of different varieties with detectable levels of aflatoxins. \\
\hline Peanut variety & \multicolumn{3}{c}{ Busia } & \multicolumn{2}{c}{ Kisii Central } \\
\cline { 2 - 5 } & $\mathbf{N}$ & $\mathbf{9}$ & $\mathbf{n}$ & $\mathbf{\%}$ \\
\hline Valencia red & $58^{\text {a }}$ & 58.6 & $89^{\mathrm{b}}$ & 87.3 \\
Uganda local red & 19 & 19.2 & 5 & 4.9 \\
Homabay local & 20 & 20.2 & 8 & 7.8 \\
Local red & 2 & 2.0 & 0 & 0.0 \\
Total & $\mathbf{9 9}$ & $\mathbf{1 0 0}$ & $\mathbf{1 0 2}$ & $\mathbf{1 0 0}$ \\
\hline
\end{tabular}

${ }^{\mathrm{a}}$ and ${ }^{\mathrm{b}}=$ Peanuts samples of Valencia red variety had significantly higher rate of aflatoxin contamination in the two districts $(\mathrm{F}=13.15, \mathrm{df}=3, \mathrm{P}=0.015)$. 
Table 3. Association between levels of total aflatoxin categories and the varieties of peanut samples from the two study districts.

\begin{tabular}{|c|c|c|c|c|c|c|}
\hline \multirow{2}{*}{ District } & \multirow{2}{*}{ Peanut variety } & \multirow{2}{*}{$\mathbf{n}$} & \multicolumn{4}{|c|}{ Levels of total Aflatoxin categories $(\mu \mathrm{g} / \mathrm{kg})$} \\
\hline & & & $\leq 4$ & $>4$ to $\leq 10$ & $>10$ to $\leq 20$ & $>20$ \\
\hline \multirow{4}{*}{ Busia } & Valencia red & 58 & $88.2 \%$ & $5.1 \%$ & $0.0 \%$ & $6.7 \%$ \\
\hline & Uganda local red & 19 & $76.2 \%$ & $4.8 \%$ & $0.0 \%$ & $19 \%$ \\
\hline & Homabay local & 20 & $80.0 \%$ & $20.0 \%$ & $0.0 \%$ & $0.0 \%$ \\
\hline & Local red & 2 & $0.0 \%$ & $0.0 \%$ & $0.0 \%$ & $100 \%$ \\
\hline \multirow{3}{*}{ Kisii Central } & Valencia red & 89 & $5.6 \%$ & $4.5 \%$ & $10.1 \%$ & $79.8 \%$ \\
\hline & Uganda local red & 5 & $0.0 \%$ & $0.0 \%$ & $20.0 \%$ & $80.0 \%$ \\
\hline & Homabay local & 8 & $0.0 \%$ & $0.0 \%$ & $12.5 \%$ & $87.5 \%$ \\
\hline
\end{tabular}

$\mathbf{n}=$ Peanut samples of each variety from the two study districts in the EU, KEBS and USFDA regulatory limits for total aflatoxins.

variety from Busia had aflatoxin levels of above $>20 \mu \mathrm{g} / \mathrm{kg}$. Ninety three (93\%) and $81 \%$ of peanuts samples of Valencia red and Uganda local red varieties respectively from Busia were within the KEBS regulatory limits of $\leq 10 \mu \mathrm{g} / \mathrm{kg}$ total aflatoxins. All the samples of Uganda local red and Homabay local varieties from Kisii Central had total aflatoxin levels exceeding $>10$ to $\leq 20 \mu \mathrm{g} / \mathrm{kg}$ while only $4.5 \%$ samples of the Valencia red variety had total aflatoxins of $\leq 10 \mu \mathrm{g} / \mathrm{kg}$ (Table 3). Kolomogorov-Smirnoff (K-S) test showed that peanuts samples from Busia district within $\leq 10 \mu \mathrm{g} / \mathrm{kg}$ total aflatoxin category was significantly higher compared to Kisii Central (K-S $=124, \mathrm{P}=0.033$ ).

Peanut samples, 93.3\% and 80\% of Valencia red and Uganda local red varieties respectively from Busia were within the USFDA regulatory limits of $\leq 20 \mu \mathrm{g} / \mathrm{kg}$ (Table 3). Twenty (20\%) percent of peanuts of Uganda local red variety from Kisii Central had total aflatoxin levels within the USFDA regulatory limit of $\leq 20 \mu \mathrm{g} / \mathrm{kg}$ while $12.5 \%$ and $10.1 \%$ of Homabay local and Valencia red peanut varieties this district had total aflatoxin levels of $\leq 20 \mu \mathrm{g} / \mathrm{kg}$ (Table 3). Mann-Whitney U two sample test showed that the distribution of samples in the levels of total aflatoxin categories from the two study districts were significantly different $(\mathrm{W}=226.0, \mathrm{P}=0.038)$. However, the resulting distribution showed that in Busia district, the distribution was skewed to the left $(\leq 4 \mu \mathrm{g} / \mathrm{kg}$ category) while in Kisii Central district, the distribution was skewed to the right, $>20 \mu \mathrm{g} / \mathrm{kg}$ category (Table 3).

\subsubsection{Types of Aflatoxins Identified in the Peanuts from the Two Study Districts}

All the 201 peanut samples from both Busia and Kisii Central districts with detectable levels of aflatoxins were analyzed for the different types of aflatoxins. All the four aflatoxin types commonly found in food commodities (Aflatoxin B1, Aflatoxin B2, Aflatoxin G1 and Aflatoxin G2) were found to be contaminating peanuts from the two districts and all the 4 peanut varieties analyzed. Overall, the four types of aflatoxins identified (B1, B2, G1 and G2) were at higher levels in peanuts from Kisii Central than those from Busia. The most common aflatoxin type found at the highest concentration in samples from both districts was Aflatoxin B1 at $0.0-115.15 \mu \mathrm{g} / \mathrm{kg}$ with a median value of $57.58 \mu \mathrm{g} / \mathrm{kg}$ and $1.30-510 \mu \mathrm{g} / \mathrm{kg}$ (median = 254.35) in Busia and Kisii Central respectively $(\mathrm{t}=12.4, \mathrm{P}=0.034)$. Aflatoxin B2 levels in the peanuts from Busia and Kisii Central were at 0.0 - 46.23 $\mu \mathrm{g} / \mathrm{kg}$ (median $=23.12 \mu \mathrm{g} / \mathrm{kg}$ ) and $0.08-48.27 \mu \mathrm{g} / \mathrm{kg}$, median $=24.10 \mu \mathrm{g} / \mathrm{kg}$ respectively (Table 4 ).

The levels of Aflatoxin type G1 were $0.0-34.90 \mu \mathrm{g} / \mathrm{kg}$ and $0.0-43.98 \mu \mathrm{g} / \mathrm{kg}$ in peanuts from Busia and Kisii Central respectively. Aflatoxin type G2 had the least levels at $0.01-15 \mu \mathrm{g} / \mathrm{kg}$ and $0.0-26.38 \mu \mathrm{g} / \mathrm{kg}$ in peanuts from Busia and Kisii Central districts respectively (Table 4). The levels of aflatoxin types B1, B2, G1 and G2 were higher in peanuts from Kisii Central than in Busia district (Table 4) although the difference between the levels of the toxin types in the two districts was not significant $(t=1.08, \mathrm{P}=0.060)$.

The levels of Aflatoxins B1 in peanuts from the two districts were grouped into two categories $(\leq 5 \mu \mathrm{g} / \mathrm{kg},>5$ $\mu \mathrm{g} / \mathrm{kg}$ ) based on KEBS Aflatoxin B1 regulatory limits of $\leq 5 \mu \mathrm{g} / \mathrm{kg}$. Out of a total of 201 peanuts samples from the two districts analyzed for aflatoxin B1, 103 (51.2\%) samples had levels within the KEBS accepted limits while 98 (48.8\%) had levels above $>5 \mu \mathrm{g} / \mathrm{kg}$. Chi-Square test showed that most of peanuts (89.9\%) from Busia had Aflatoxin B1 levels within the KEBS accepted regulatory limit compared to peanuts from Kisii Central with $14(13.7 \%)$ samples $\left(\chi^{2}=5.23, \mathrm{P}=0.16\right)$. Most of the samples from Kisii Central district (86.3\%) had aflatoxin B1 levels above $5 \mu \mathrm{g} / \mathrm{kg}$ and therefore were not safe for human consumption (Table 5). 
Table 4. Levels of the different types of aflatoxins identified in peanut samples from the two study districts.

\begin{tabular}{cccccc}
\hline & \multicolumn{3}{c}{ Aflatoxin levels $(\boldsymbol{\mu g} / \mathbf{k g})$} \\
\cline { 2 - 5 } Type of Aflatoxin & \multicolumn{2}{c}{ Busia } & \multicolumn{2}{c}{ Kisii Central } \\
\cline { 2 - 6 } & Range & Median & Range & Median \\
\cline { 2 - 6 } & $0.0-115.15$ & 57.58 & $1.30-510$ & 254.35 \\
Aflatoxin B1 & $0.0-46.23$ & 23.12 & $0.08-48.27$ & 24.10 \\
Aflatoxin B2 & $0.0-34.90$ & 17.45 & $0.0-43.98$ & 21.99 \\
Aflatoxin G1 & $0.01-15.0$ & 7.50 & $0.0-26.38$ & 13.19 \\
Aflatoxin G2 & & & & \\
\hline
\end{tabular}

Table 5. Aflatoxin B1 levels in peanuts samples collected from the two study areas.

\begin{tabular}{ccccc}
\hline \multirow{2}{*}{ District } & Type of aflatoxin & \multicolumn{2}{c}{ Peanut samples having different levels of aflatoxin B1 } \\
\cline { 3 - 4 } & & $\leq \mathbf{5} \mathbf{~ g} / \mathbf{k g}^{\mathbf{a}}$ & $>\mathbf{5} \mathbf{~ g} / \mathbf{k g}$ & Total samples \\
\hline Busia & Aflatoxin B1 & $89(89.9 \%)$ & $10(10.1 \%)$ & $99(100 \%)$ \\
Kisii Central & Aflatoxin B1 & $14(13.7 \%)$ & $88(86.3 \%)$ & $102(100 \%)$ \\
Total & & $\mathbf{1 0 3 ( 5 1 . 2 \% )}$ & $\mathbf{9 8 ( 4 8 . 8 \% )}$ & $\mathbf{2 0 1}(\mathbf{1 0 0 \% )}$ \\
\hline
\end{tabular}

$\mathrm{a}=$ Aflatoxin category with significant number of peanuts from Busia district in the KEBS accepted regulatory limit.

\subsubsection{Association between Aflatoxin Types B1, B2, G1 and G2 Levels and Categories of Total Aflatoxin in Peanuts}

Incidences of aflatoxin B1 and aflatoxin B2 in the total aflatoxin category of $0 \leq 4 \mu \mathrm{g} / \mathrm{kg}$ were higher in peanuts from Busia compared to peanuts from Kisii Central district $\left(\chi^{2}=13.01, \mathrm{P}=0.009\right)$. Approximately, $90 \%$ of peanuts of the different varieties from Busia had aflatoxin types B1, B2, G1 and G2 levels and were in the total aflatoxin category of $0 \leq 4 \mu \mathrm{g} / \mathrm{kg}$. Most of peanuts from Kisii Central district (71.5\%) had aflatoxin B1 levels in the total aflatoxin category of $>20 \mu \mathrm{g} / \mathrm{kg}$. However, $58.9 \%$ of peanuts from the same study district had aflatoxin type B2 levels in the total aflatoxin category of $0 \leq 4 \mu \mathrm{g} / \mathrm{kg}$ (Table 6). The incidences of aflatoxins type B1 and $\mathrm{B} 2$ in peanuts from the two study districts were significantly different $\left(\chi^{2}=14.82, \mathrm{P}=0.004\right)$. The incidences of aflatoxins type G1 and G2 were not significantly different when compared for the two districts $\left(\chi^{2}=19.01, \mathrm{P}=\right.$ 0.123). The levels of aflatoxins types G1 and G2 were however higher ( $>81 \%)$ in peanuts from both districts in total aflatoxins category, $0 \leq 4 \mu \mathrm{g} / \mathrm{kg}$ (Table 6). Lower incidences ranging from $0 \%-14.7 \%$ of aflatoxins types G1 and G2 were obtained in peanuts in the total aflatoxin category of $>4 \leq 10 \mu \mathrm{g} / \mathrm{kg}$ in both districts (Table 6).

It was noted that most of the peanuts (mean $75.61 \%$ ) analyzed from the two study districts had aflatoxin levels within the total aflatoxin category of $0 \leq 4 \mu \mathrm{g} / \mathrm{kg}$ compared to the other categories $(\mathrm{F}=23.61, \mathrm{df}=3, \mathrm{P}=$ 0.001), Table 7.

The mean incidences of Aflatoxin types G1 and G2 respectively were in the range of $0 \leq 4 \mu \mathrm{g} / \mathrm{kg}$ for $93.15 \%$ and $85.7 \%$ of peanuts samples from the two study districts. Most of the peanuts samples which were in total aflatoxin category of $>4$ to $\leq 10 \mu \mathrm{g} / \mathrm{kg}$ ) had Aflatoxin B2 levels within $>10 \leq 20 \mu \mathrm{g} / \mathrm{kg}$ and those which had Aflatoxin B1 were in total aflatoxin category, $>20 \mu \mathrm{g} / \mathrm{kg}$ (Table 8).

Kruskal-Wallis test revealed that the overall mean incidences of Aflatoxin B2 in samples from the two districts in the different total aflatoxin categories were different, $74.55 \%, 8.85 \%, 10.3 \%$ and $7.3 \%(\mathrm{H}=17.63, \mathrm{P}=$ 0.03 ) for Aflatoxin categories; 0 to $\leq 4 \mu \mathrm{g} / \mathrm{kg},>4$ to $\leq 10 \mu \mathrm{g} / \mathrm{kg}, 10$ to $\leq 20 \mu \mathrm{g} / \mathrm{kg}$ and $>20 \mu \mathrm{g} / \mathrm{kg}$ respectively. Similarly, the incidence of aflatoxin G2 in samples was $85.7 \%, 4.45 \%, 2.95 \%$ and $1.5 \%(\mathrm{H}=16.50, \mathrm{P}=0.021)$ in Aflatoxin categories 0 to $\leq 4 \mu \mathrm{g} / \mathrm{kg},>4$ to $\leq 10 \mu \mathrm{g} / \mathrm{kg}, 10$ to $\leq 20 \mu \mathrm{g} / \mathrm{kg}$ and $>20 \mu \mathrm{g} / \mathrm{kg}$ respectively.

\section{Discussion}

\subsection{Peanuts Varieties from Busia and Kisii Central Districts}

In both districts, peanuts of Valencia red variety had the highest number of samples, 59 and 89 from Busia and Kisii Central districts respectively which were significantly different from the other varieties. This could have been attributed by the fact that Valencia red variety is the most common improved variety of peanuts planted by farmers in the western region of Kenya [10] compared to other varieties in the study areas. The variety tends to 
Table 6. Association between levels of aflatoxin types and the categories of total aflatoxin in peanuts from the two districts.

\begin{tabular}{|c|c|c|c|c|c|}
\hline \multirow{2}{*}{ District } & \multirow{2}{*}{ Type of Aflatoxin } & \multicolumn{4}{|c|}{ Percentage $(\%)$ of peanuts samples with different levels of total Aflatoxin categories $(\mu \mathrm{g} / \mathrm{kg})$} \\
\hline & & $0 \leq 4$ & $>4 \leq 10$ & $>\mathbf{1 0} \leq \mathbf{2 0}$ & $>\mathbf{2 0}$ \\
\hline \multirow{4}{*}{ Busia } & Aflatoxin B1 & $90.2 \%$ & $0.0 \%$ & $0.0 \%$ & $9.8 \%$ \\
\hline & Aflatoxin B2 & $90.2 \%$ & $0.0 \%$ & $0.0 \%$ & $9.8 \%$ \\
\hline & Aflatoxin G1 & $91.2 \%$ & $4.9 \%$ & $2.0 \%$ & $1.9 \%$ \\
\hline & Aflatoxin G2 & $90.0 \%$ & $5.0 \%$ & $3.0 \%$ & $2.0 \%$ \\
\hline \multirow{4}{*}{ Kisii Central } & Aflatoxin B1 & $7.9 \%$ & $13.8 \%$ & $6.8 \%$ & $71.5 \%$ \\
\hline & Aflatoxin B2 & $58.9 \%$ & $17.7 \%$ & $20.6 \%$ & $4.8 \%$ \\
\hline & Aflatoxin G1 & $95.1 \%$ & $3.9 \%$ & $1.0 \%$ & $0.0 \%$ \\
\hline & Aflatoxin G2 & $81.4 \%$ & $14.7 \%$ & $2.9 \%$ & $1.0 \%$ \\
\hline
\end{tabular}

Table 7. Mean (\%) of number of peanuts samples with different levels of total aflatoxins.

\begin{tabular}{ccccc} 
& \multicolumn{4}{c}{ Aflatoxin levels $(\boldsymbol{\mu g} / \mathbf{k g})$} \\
\cline { 2 - 5 } & $\mathbf{0} \leq \mathbf{4}$ & $\mathbf{> 4} \leq \mathbf{1 0}$ & $\mathbf{> 1 0} \leq \mathbf{2 0}$ & $\mathbf{2 0}$ \\
\hline Mean (\%) peanut samples & 75.61 & 7.50 & 4.54 & 12.60 \\
Standard error & 10.5 & 2.44 & 2.42 & 8.52 \\
\hline
\end{tabular}

Table 8. Average in percentage of peanuts with aflatoxin levels and types in peanuts samples from the two study districts.

\begin{tabular}{ccccc}
\hline \multirow{2}{*}{ Type of Aflatoxin } & Mean percentage (\%) of peanuts samples with different levels of total Aflatoxin categories $(\boldsymbol{\mu g} / \mathbf{k g})^{\mathbf{x}}$ \\
\cline { 2 - 4 } & $\mathbf{0} \leq \mathbf{4}$ & $\mathbf{> 4} \leq \mathbf{1 0}$ & $\mathbf{> 1 0} \leq \mathbf{2 0}$ & $\mathbf{2 0}$ \\
\hline Aflatoxin B1 & $49.05 \%$ & $6.9 \%$ & $3.4 \%$ & $40.65 \%$ \\
Aflatoxin B2 & $74.55 \%$ & $8.85 \%$ & $10.3 \%$ & $7.3 \%$ \\
Aflatoxin G1 & $93.15 \%$ & $4.4 \%$ & $1.5 \%$ & $0.95 \%$ \\
Aflatoxin G2 & $85.7 \%$ & $4.45 \%$ & $2.95 \%$ & $1.5 \%$ \\
\hline
\end{tabular}

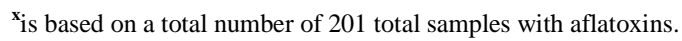

be preferred due to higher yield and resistance to diseases which may also reduce their susceptibility to infection by Aspergillus species compared to the local varieties [10]. The result of this study is in line with that of Mutegi et al., 2010 [10] who documented a higher number of peanuts of Valencia red variety than the other varieties in the study areas.

In this study, there were few samples of peanuts of local varieties; Uganda local red (26), Homabay local (28) and Local red (2) from the two study districts. It is possible that peanuts farmers avoid planting these varieties because they have low yields and are less resistant to diseases [18]. Moreover, local varieties of peanuts such as Uganda local red, Homabay local and Local red, have been reported to be more susceptible to rosette virus and mould than improved varieties [14], and a positive correlation between the diseases and aflatoxin contamination of peanuts have been documented in other studies [19]-[21]. These findings are consistent with those reported in previous studies by Mutegi et al., 2010 [22].

\subsection{Incidence of Aflatoxin in Peanuts from Busia and Kisii Central Districts}

Aflatoxin was detected in almost all the peanut samples of the different varieties from Busia (97.06\%) and Kisii Central districts (100\%) as shown in Figure 1. This could have been attributed by the frequent rainfall (wetter) in Kisii Central compared to drier climatic conditions in Busia district. The wetter and more humid conditions tends to aggravate aflatoxins levels as it enhances the growth of Aspergillus species and production of aflatoxins in peanuts compared to drier climatic condition [23]. Previously, it was documented that significant correlations existed between weather conditions and aflatoxin levels, whereby a wet and humid climate tends to favor the growth of Aspergillus species and increase aflatoxin production in peanuts [22] [24]. Similar results were reported in previous studies in peanuts [10] [24] [25] and a in a survey of maize samples from Nigeria [26]. 


\subsection{Levels and Types of Aflatoxins Contaminating the Different Varieties of Peanuts in Busia and Kisii Central Districts}

In this study, the levels and types of aflatoxins detected in peanuts from the two districts were compared with the Kenya Bureau of Standards (KEBS), European Union (EU) and United States Food and Drug Administration (USFDA) regulatory limits for total and types of aflatoxins in foods in order to determine whether they were safe for human consumption.

\subsubsection{Peanuts of Different Varieties Analyzed with Detectable Levels of Aflatoxins}

Most peanuts (50.7\%) of different varieties from Kisii Central district were contaminated with aflatoxins compared to those from Busia (49.3\%). The significantly higher number of peanuts samples from Kisii Central that were contaminated with aflatoxins compared to Busia could have been contributed to different climate conditions in the districts; wetter and humid conditions often occurring in Kisii Central and drier conditions in Busia. Wet and humid conditions tend to aggravate growth of Aspergillus species especially Aspergillus flavus and parasiticus and therefore more production of aflatoxins compared to dry areas like Busia. This is probably because a high moisture condition does not allow sufficient drying of peanuts that are in most cases dried on bare ground or polythene sheets in homesteads and therefore facilitating the fungi contamination and hence higher production of aflatoxins. The results are in line with previous studies which documented a significant association between climate and aflatoxin levels, whereby a wet and humid climate enhances production of aflatoxins in peanuts compared to drier areas [10]). Kaaya et al., 2006 [23], documented higher aflatoxin levels though in maize samples from humid areas compared to drier areas in Uganda.

Peanuts of Valencia red variety from both districts had a significantly higher number of samples with aflatoxin contamination than the other varieties, 89 (87.3\%) and 58 (58.6\%) from Kisii Central and Busia respectively $(\mathrm{F}=13.15$, $\mathrm{df}=3, \mathrm{P}=0.015)$. This could probably be due to the fact that peanuts of Valencia red variety are the commonly grown in the study areas and therefore more samples were collected compared to other varieties. The results are consistent with previous study on peanuts which documented Valencia red variety peanuts as the mostly grown in western region and had the highest number of samples compared to the other varieties analyzed in the study contaminated with aflatoxins [10]. It is important to note that a higher proportion of peanuts of Valencia red variety from Kisii Central were contaminated with aflatoxins compared to those from Busia district. This could be due to the wet and humid climate in Kisii Central compared to Busia (dry) whereby the higher moisture contents facilitates the growth of Aspergillus species and therefore high Aflatoxin levels production. The result is in line with a report of previous study done on peanuts by Mutegi et al., 2009 [10].

More peanuts samples of Uganda local red, Homabay local and Local red varieties from Kisii Central district had detectable levels of aflatoxins compared to those from Busia district (Table 2). This could probably due to higher number of samples of the peanut analyzed from Kisii Central district as compared to those from Busia. It might also have been contributed by more susceptibility to colonization by Aflatoxin producing Aspergillus species as they are local varieties. Moreover, the local peanut varieties; Homabay local, Uganda local red and Local red have been reported to be susceptible to stem rot, mould and rosette virus [14], and a positive correlations between these diseases and aflatoxin contamination of peanuts have been documented in previous studies [20] $[21]$.

\subsubsection{Levels of Total Aflatoxins in Different Varieties of Peanuts from the Two Study Districts} In this study, the levels of aflatoxin in peanuts from the two study districts were investigated. The aflatoxin levels were identified and compared with KEBS, EU and USFDA regulatory limits of total aflatoxins in foods including peanuts. Overall, the levels of total aflatoxin ranges in peanuts from Kisii Central were higher (ranges were 1.63 to $591.1 \mu \mathrm{g} / \mathrm{kg}$ ) compared to peanuts from Busia (ranged from 0.1 to $268 \mu \mathrm{g} / \mathrm{kg}$ ). The higher aflatoxin levels in peanuts from Kisii Central district could have been attributed by high moisture contents in peanuts due to wet and humid climate in the area which increases colonization of Aspergillus species and therefore high aflatoxin production compared to Busia district with dry weather conditions. The study is in line with a previous study on peanuts [10] [27]. In another study, aflatoxins levels in maize samples were higher in wet areas compared to dry areas [23]. Similar results were obtained in a survey of peanut samples from Nigeria [26].

In this study, the results showed that peanuts of local varieties and those from more humid areas were more contaminated with aflatoxins than those from improved varieties and less humid areas. Peanuts of Local red variety from Busia district had the highest level of aflatoxins at $268 \mu \mathrm{g} / \mathrm{kg}$ compared to other varieties analyzed 
while in Kisii Central district, peanuts of Valencia red variety had the highest aflatoxin levels at $591.07 \mu \mathrm{g} / \mathrm{kg}$. This result could have been attributed by more susceptibility to aflatoxins contamination of peanuts of Local red variety in Busia district while in Kisii Central, the more humid and wetter climatic conditions may have contributed to increased moisture in peanuts which facilitated the growth of Aspergillus species and production of aflatoxins even in Valencia red, an improved peanuts variety. The results are in line with a previous study on peanuts by Mutegi et al., 2009 [10] who reported high aflatoxins levels in peanuts of Local red and Valencia red varieties.

Most of peanuts from the different varieties in Busia except Local red were fit for human consumption based on the EU total aflatoxins levels regulatory limits $(\leq 4 \mu \mathrm{g} / \mathrm{kg})$ compared to those in Kisii Central district. This is because $88.2 \%, 76.2 \%$ and $80 \%$ of Valencia red, Uganda local red and Homabay local samples from Busia had total aflatoxin levels of $\leq 4 \mu \mathrm{g} / \mathrm{kg}$ compared to only $5.6 \%$ and $0 \%$ of peanuts of Valencia red, Uganda local red and Homabay local respectively from Kisii Central district in the same category.

Based on the KEBS regulatory limit of $\leq 10 \mu \mathrm{g} / \mathrm{kg}$, the same trend was observed whereby over $81 \%$ of similar peanuts varieties from Busia had aflatoxin levels below the KEBS regulatory limit while only $10 \%$ of peanuts of Valencia red and none of the other varieties from Kisii Central had aflatoxin levels of $\leq 10 \mu \mathrm{g} / \mathrm{kg}$ (Table 3). This was contributed by more aflatoxins contamination of peanuts in Kisii Central district compared to those from Busia district. The increase in aflatoxin contamination of peanuts in Kisii Central district compared to those from Busia district could have been contributed by the more wetter and humid climate condition than in Busia. This resulted in fewer peanuts samples in the KEBS regulatory limits and therefore most of the peanuts from Kisii Central were unfit for human consumption. The results are similar to reports in previous studies done on peanuts [10] [28].

Based on the USFDA regulatory limit of $>20 \mu \mathrm{g} / \mathrm{kg}$, over $81 \%$ of Valencia red, Homabay local and Uganda local red peanuts varieties from Busia had aflatoxin levels of below the USFDA regulatory limit while only $11.2 \%, 12.5 \%$ and $20 \%$ of Valencia red, Homabay local and Uganda local red varieties respectively from Kisii Central had aflatoxin levels of below the USFDA regulatory limit (Table 3). The result was contributed by peanuts of all the varieties from Kisii Central district more contaminated with aflatoxins compared to those from Busia. Therefore, most of peanuts from Busia district (over 81\%) and 20\% and below of peanuts from Kisii Central were fit for human consumption. The results are consistent with a previous study done by Mutegi et al., 2010 [10].

It was noted that all the samples of Local red variety which was sampled only from Busia district had total aflatoxin levels of $>20 \mu \mathrm{g} / \mathrm{kg}$. These peanuts were highly contaminated with aflatoxins and therefore unfit for human consumption based on USFDA regulatory limit. This could attributed to the fact that local peanuts varieties such as Local red and Uganda red are reported to be more susceptible to moulds, stem rot and other diseases [14] of which the diseases correlates with growth of Aspergillus species and therefore more aflatoxin production. Similar results have been reported in previous studies [20] [21].

\subsubsection{Types of Aflatoxins Identified in Peanuts Samples from the Two Study Districts}

In this study, the four types of aflatoxins identified (B1, B2, G1 and G2) were at higher levels in peanuts from Kisii Central than those from Busia. Perhaps due to wetter humid conditions in Kisii Central district compared to Busia. There were high incidences of Aflatoxin B1 and B2 types across the samples in both districts, and a significantly higher incidence of Aflatoxin type G1 in Kisii Central compared to Busia district. As expected, the high incidence of Aspergillus flavus S-strain reported in

Kisii Central was associated with greater aflatoxin production. This particular strain has been documented to be responsible for production of aflatoxins and especially the more toxic B toxins particularly in more humid and wetter areas [29]. The high incidence of Aspergillus flavus S-strain identified in this study could therefore have been responsible for the high incidences of the Aflatoxin B1 and B2 types in the study districts. A similar trend of result has been reported in other studies, whereby the Aspergillus flavus $S$-strain is found to be the main source of aflatoxin in foods including peanuts in the United States [30] and in maize from Kenya [29]. The result of this study corresponds well with other studies that documented similar predominance in Aflatoxin B1 [31] [32].

It was observed that as the total aflatoxin levels increased, the incidence of aflatoxin B1 generally increased which accords well with findings of Horn and Dorner, 1999 [33], who found a positive association between Aflatoxin B1 production and increased incidences of both $S$ - and $L$-strains of $A$. flavus. Despite that majority of 
peanuts especially those from Busia being safe for human consumption compared to those from Kisii Central, according to EU and KEBS regulatory limits [10], the high incidences of Aspergillus flavus S-strain and Aspergillus flavus $L$-strain reported in this study, implies a likelihood of increased aflatoxin levels if safe pre- and post-harvest aflatoxin contamination management measures are not adhered to.

In spite of the fact that there was low incidence of Aspergillus parasiticus (mean occurrence of 9.3\%) in this study, it was the third most isolated Aspergillus species from Aspergillus flavus $S$ and Aspergillus flavus Lstrains, a fact that the species could have contributed to high levels of aflatoxins especially aflatoxin G1 type in Kisii Central district. The wetter and more humid growth conditions in Kisii Central compared to Busia could have contributed to increased production of aflatoxin G1 type by the Aspergillus parasiticus which produces exclusively toxin G1 and subsequently significantly higher aflatoxin level of the toxin type in Kisii Central. The result is in line with previous report on peanuts, which documented Aspergillus parasiticus as one of the key fungus that contributes to high production of aflatoxin G1 especially in wet areas [10]. In addition to producing aflatoxin G1 and G2, A. parasiticus is also capable of producing of aflatoxin B1 and B2 [28]. This could have contributed to the high proportions of the two aflatoxins types in peanuts particularly those from Kisii Central district.

Most of peanuts samples (89.9\%) of different varieties from Busia district had Aflatoxin B1 levels below $\leq 5$ $\mu \mathrm{g} / \mathrm{kg}$ and were fit for human consumption based on based on KEBS Aflatoxin B1 regulatory limit of $\leq 5 \mu \mathrm{g} / \mathrm{kg}$. Only $13.7 \%$ of peanuts samples from Kisii Central had Aflatoxin B1 levels within the KEBS regulatory limit and therefore were fit for human consumption while $86.3 \%$ had levels exceeding $\leq 5 \mu \mathrm{g} / \mathrm{kg}$. This could be explained by the higher incidence of Aspergillus flavus S-strain (60.2\%) in peanuts from Kisii Central compared to those from Busia (29.4\%). The high incidence of this strain in the district may imply higher production of aflatoxin B1 in peanuts from the study area. Although there was no significant difference in incidences of Aspergillus flavus S-strain (60.2\%) and Aspergillus flavus L-strain (58.8\%) in peanuts from Busia district, most of the $L$ strain A. flavus were atoxigenic which resulted to low production of aflatoxins including aflatoxin B1 in peanuts from Busia. The result corresponds with previous studies on peanuts by Mutegi et al., 2009 [10].

\subsection{Study Limitations}

Only peanut producers from Busia and Kisii Central districts in the western Kenya participated in this study. More districts in the peanut growing region could not be included in the study due to financial constraints. In cases where household heads were not available for personal interviews, it was assumed that the information given by the family members present was credible.

\section{Conclusion}

The main peanut variety grown in the two study areas was Valencia red. Aflatoxin was detected in all peanuts from Kisii Central and $\mathbf{9 7 . 0 6 \%}$ in those from Busia. The level of aflatoxin varied considerably among samples although majority of peanuts of the different varieties had aflatoxin levels within the Kenya Bureau of Standards and European Union regulatory limits for total aflatoxins for human consumption. Improved variety (Valencia red) had significantly lower aflatoxin contamination compared to local varieties (Uganda local red, Homabay local and Local red). Aflatoxins B1, B2, G1 and G2 were found in peanuts; B1 was the most predominant in both districts. A continuous assessment on the levels of aflatoxins should be done by the relevant stakeholders in peanuts and other key foods in the study areas for example maize.

\section{Acknowledgements}

We would like to thank Kenyatta University Ethics Review Committee for the approval of this study. We also acknowledge the National Commission for Science, Technology and Innovation (NACOSTI), Kenya for issuing a Research permit for the study. We are grateful to all the peanuts farmers for their cooperation during sample collection. Finally, we are also grateful to George K. Gathumbi of Bora Limited Laboratory, Kenya for his contribution in this research work.

\section{References}

[1] Khlangwiset, P., Shepherd, G. and Wu, F. (2011) Aflatoxins and Growth Impairment: A Review. Critical Reviews in 
Toxicology, 118, 817-824. http://dx.doi.org/10.3109/10408444.2011.575766

[2] Shephard, G. (2003) Aflatoxin and Food Safety: Recent African Perspectives. Journal of Toxicology, 22, 267-286. http://dx.doi.org/10.1081/txr-120024094

[3] Strosnider, H., Azziz-Baungartner, A., Banziger, M., Bhat, R., Brune, M. DeCock, K. et al. (2006) Workgroup Report: Public Health Strategies for Reducing Aflatoxin Exposure in Development Countries. Environmental Health Perspectives, 114, 1989-1903. http://dx.doi.org/10.1289/ehp.9302

[4] Fung, F. (2004) Health Effects of Mycotoxins: A Toxicological Overview. Journal of Clinical Toxicology, 42, $217-234$. http://dx.doi.org/10.1081/clt-120030947

[5] Waliyar, F., Kumar, P., Traore, A., Ntare, B., Diarra, B. and Kodio, R. (2008) Pre- and Post-Harvest Management of Aflatoxin Contamination in Peanuts. Cromwell Journal of Health, 209-218.

[6] WHO (2008) World Health Statistics. WHO Press, Geneva, 1-5.

[7] Liu, T. and Wu, F. (2010) Global Burden of Aflatoxin Induced Hepatocellur Carcinoma. A Risk Assessment Environmental Health Perspective, 118, 818-824. http://dx.doi.org/10.1289/ehp.0901388

[8] Lewis, L., Onsongo, M., Njapau, H., Schur-Rogers, H., Laber, G., Kieszak, S., et al. (2005) Aflatoxin Contamination of Commercial Maize Products during an Outbreak of Acute Aflatoxicosis in Eastern and Central Kenya. Environmental Health Perspective, 113, 1763-1767. http://dx.doi.org/10.1289/ehp.7998

[9] Williams, J., Phillips, T., Jolly, P., Stiles, J. and Aggarwal, D. (2004) Human Aflatoxicosis in Developing Countries: A Review of Toxicology, Exposure, Potential Health Consequences, and Interventions. American Journal of Clinical Nutrition, 80, 1106-1122.

[10] Mutegi, C., Ngugi, H., Hendriks, S. and Jones, R. (2009) Prevalence and Factors Associated with Aflatoxin Contamination of Peanuts from Western Kenya. International Journal of Food Microbiology, 130, 27-34. http://dx.doi.org/10.1016/j.ijfoodmicro.2008.12.030

[11] Gong, Y., Cardwell, K., Hounsa, A., Egal, S., Turner, P., Hall, A., et al. (2002) Dietary Aflatoxin Exposure and Impaired Growth in Young Children from Benin and Togo: Cross-Sectional Study. British Medical Journal, 325, 20-21. http://dx.doi.org/10.1136/bmj.325.7354.20

[12] Kenya Bureau of Standards (2007) Raw Groundnut for Table Use. Kenya Bureau of Standards Documentation Centre, Nairobi.

[13] Mutegi, C., Wagacha, M., Kimani, J., Otieno, G., Wanyama, R., Hell, K., et al. (2013) Incidence of Aflatoxin in Peanuts from Markets in Western, Nyanza and Nairobi Provinces of Kenya and Related Market Traits. Journal of Stored Products Research, 52, 118-127. http://dx.doi.org/10.1016/j.jspr.2012.10.002

[14] Ogwang, T. (2006) Status of Groundnut Production in Busia District: Lucrative Legume Project. Proceedings of the Stakeholders Meeting, Milimani Resort, 10 February 2006.

[15] Kipkoech, A., Okiror, M., Okalebo, J. and Maritim, H. (2007) Production Efficiency and Economic Potential of Different Soil Fertility Management Strategies among Groundnut Farmers of Kenya. Science World Journal, 2, 5171477951.

[16] Whitaker, T. (2006) Sampling Foods for Mycotoxin. Food Addictives and Contaminants, 23, 50-61. http://dx.doi.org/10.1080/02652030500241587

[17] Bragulat, M., Abarca, M. and Cabanas, F. (2001) An Easy Screening Method for Fungi Producing Ochratoxin A in Pure Culture. International Journal Food Microbiology, 71, 139-144. http://dx.doi.org/10.1016/S0168-1605(01)00581-5

[18] Hell, K., Cardwell, K. and Poehling, H. (2003) Relationship between Management Practices, Fungal Infection and Aflatoxin for Stored Maize in Benin. Journal of Phytopathology, 151, 690-698. http://dx.doi.org/10.1046/j.1439-0434.2003.00792.x

[19] Udoh, J., Cardwell, K. and Ikotun, T. (2000) Storage Structures and Aflatoxin Content of Maize in Five Agro-Ecological Zones of Nigeria. Journal of Stored Products Research, 36, 187-201. http://dx.doi.org/10.1016/S0022-474X(99)00042-9

[20] Kasno, A. (2004) Prevention of Aspergillus flavus Infection and Aflatoxin Contamination in Groundnut. Journal Penelitian dan Pengembangan Pertanian, 23, 75-81.

[21] Robertson-Hoyt, L., Payne, G., Isakeit, T., Maragos, C., Molnar, T. and Holland, J. (2007) Relationships among Resistances to Fusarium and Aspergillus Ear Rots and Contamination by Fumonisin and Aflatoxin in Maize. Phytopathology, 99, 311-317. http://dx.doi.org/10.1094/PHYTO-97-3-0311

[22] Mutegi, C., Hendriks, S. and Ngugi, H. (2010) The Extent of Aflatoxin and Aspergillus section flavi, Penicillium spp. and Rhizopus spp. Contamination of Peanuts from Households in Western Kenya and the Causative Factors of Contamination. Research Space, 1, 1-107. 
[23] Kaaya, A. and Kyamuhangire, W. (2006) The Effect of Storage Time and Agroecological Zone on Mould Incidence and Aflatoxin Contamination of Maize from Traders in Uganda. International Journal of Food Microbiology, 110, 217-231. http://dx.doi.org/10.1016/j.ijfoodmicro.2006.04.004

[24] Hell, K., Cardwell, K., Setamou, M. and Poehling, H. (2000) The Influence of Storage Practices on Aflatoxin Contamination in Maize in Four Agro-Ecological Zones of Benin, West Africa. Journal of Stored Products Research, 36, 365-382. http://dx.doi.org/10.1016/S0022-474X(99)00056-9

[25] Hell, K. and Mutegi, C. (2010) Aflatoxin Control and Prevention Strategies in Key Crops of Sub-Saharan Africa. African Journal of Microbiology Research, 5, 459-466.

[26] Atehnkeng, J., Ojiambo, P., Doner, M., Ikotun, T., Sikora, R., Cotty, P., et al. (2008) Distribution and Toxigenicity of Aspergillus Species Isolated from Maize Kernels from Three Agro-Ecological Zones in Nigeria. International Journal of Food Microbiology, 122, 74-78. http://dx.doi.org/10.1016/j.ijfoodmicro.2007.11.062

[27] Gachomo, E., Mutitu, E. and Kotchoni, O. (2004) Diversity of Fungal Species Associated with Peanuts in Storage and the Levels of Aflatoxins in Infected Samples. International Journal of Agriculture and Biology, 6, 955-959.

[28] Waliyar, F., Kumar, P., Traore, A., Ntare, B., Diarra, B. and Kodio, R. (2008) Pre- and Post-Harvest Management of Aflatoxin Contamination in Peanuts. Cromwell Journal of Health, 209-218.

[29] Probst, C., Njapau, H. and Cotty, P. (2007) Outbreak of an Acute Aflatoxicosis in Kenya, Identification of the Causal Agent. Applied and Environmental Microbiology, 73, 2762-2764. http://dx.doi.org/10.1128/AEM.02370-06

[30] Abbas, H. and Hemed, R. (2005) Relationships between Aflatoxin Production and Sclerotia Formation among Isolates of Aspergillus. European Journal of Plant Pathology, 112, 283-287. http://dx.doi.org/10.1007/s10658-004-4888-8

[31] Awuah, T. and Kpodo, A. (1996) High Incidence of Aspergillus flavus and Aflatoxins in Stored Groundnuts in Ghana and the Use of a Microbial Assay to Assess the Inhibitory Effects of Plant Extracts on Aflatoxin Synthesis. Mycopathologia, 134, 109-114. http://dx.doi.org/10.1007/BF00436873

[32] Mutegi, C., Hendriks, S., Jones, R., Okello, J. and Ngugi, H. (2007) Role of Collective Action and Handling Practices on Aflatoxin Contamination of Groundnuts. African Crop Science, 1, 27-31.

[33] Horn, B. and Dorner, J. (1999) Regional Differences in Production of Aflatoxin B1 and Cyclopiazonic Acid by Soil Isolates of Aspergillus flavus along a Transect within the United States. Applied Environmental Microbiology, 65, 1444-1449. 